\title{
The effect of GSK-3 $\beta$ in arsenic-induced apoptosis of malignant tumor cells: a systematic review and meta-analysis
}

\section{Xin Gao}

Shihezi University

\section{Bin Deng}

Shihezi University

\section{Shanshan Ran}

Shihezi University

Shugang Li ( $\square$ lishugang@ccmu.edu.cn )

Capital Medical University

\section{Research Article}

Keywords: arsenic, PI3K/Akt, GSK-3ß, mitochondria, apoptosis

Posted Date: February 24th, 2021

DOI: https://doi.org/10.21203/rs.3.rs-200247/v1

License: (c) (i) This work is licensed under a Creative Commons Attribution 4.0 International License. Read Full License

Version of Record: A version of this preprint was published at Toxicology Mechanisms and Methods on March 10th, 2022. See the published version at https://doi.org/10.1080/15376516.2022.2051654. 
$4{ }^{1}$ Department of Public Health, School of Medicine, Shihezi University, Xinjiang,

$5 \quad$ China

$6 \quad{ }^{2}$ School of Public Health, Capital Medical University, Beijing, China

7 Category: Original article

$8 \quad$ Xin Gao-MS(Medical Student)

$9 \quad$ Bin Deng-MS(Medical Student)

10

11

\section{The effect of GSK-3 $\beta$ in arsenic-induced apoptosis of malignant} tumor cells: a systematic review and meta-analysis
Xin $\mathrm{Gao}^{{ }^{1}}$, Bin Deng ${ }^{1}$, Shanshan $\operatorname{Ran}^{1}$, Shugang $\mathrm{Li}^{2}$ 


\section{Abstract}

Purpose: Arsenic has been reported to induce apoptosis in malignant tumor cells, therefore, it may be regarded as a treatment for some cancers. The mitochondrial apoptosis pathway, mediated by GSK-3 $\beta$, plays an important role in tumor cell apoptosis. Nonetheless, the regulation of GSK-3 $\beta$ by arsenic remains controversial.

Materials and Methods : We included 19 articles, which conducts the role of GSK-3 $\beta$ in the process of arsenic-induced tumor cell apoptosis by the meta-analysis.

Results: Compared with the control group, the expression of GSK-3 $\beta$ (SMD= $-0.92,95 \%$ CI $(-1.78,-0.06)), \mathrm{p}-\mathrm{Akt}(\mathrm{SMD}=-5.46,95 \% \mathrm{CI}(-8.67,-2.24))$ were reduced in the arsenic intervention group. Meanwhile, the combined treatment of arsenic and Akt agonist can inhibit the expression of p-GSK-3 $\beta$. Using the dose and time subgroup analysis, it was shown that the low-dose and sub-chronic arsenic exposure could inhibit the expression of $\mathrm{p}$-Akt $(\mathrm{P}<0.05)$. In the subgroup analysis of GSK-3 $\beta$ sites, arsenic could inhibit p-Akt and GSK-3 $\beta$ (Ser9) $(\mathrm{SMD}=-0.95,95 \%$ CI $(-1.56$, -0.33)). There was a dose-related effect seen between arsenic $(\leq 8 \mu \mathrm{mol} / \mathrm{L})$ and p-GSK-3 $\beta$, and the expression of p-GSK-3 $\beta$ was gradually followed by the arsenic dose. When arsenic acted on GSK-3 $\beta$ (ser9), the expression of Mcl-1 and pro-caspase-3 were dropped, while the loss rate of mitochondrial membrane potential and cleaved-caspase- 3 were increased significantly $(\mathrm{P}<0.05)$.

Conclusion: This study revealed that arsenic could inhibit the expression of GSK-3 $\beta$ (Ser9) and then induce tumor cell apoptosis. It might be correlated with arsenic inhibiting p-Akt, down-regulating GSK-3 $\beta$, and triggering the Mcl-1-mediated mitochondrial apoptosis pathway.

Keywords: arsenic, PI3K/Akt, GSK-3 $\beta$, mitochondria, apoptosis 


\section{Introduction}

Arsenic and its compounds have been reported to have therapeutic effects on certain diseases since ancient times [1]. Studies have shown that arsenic can induce tumor cell apoptosis, inhibit cancer stem-like cell growth, act as anti-angiogenesis, increase the sensitivity of chemotherapy and radiotherapy in recent years [2]. Thus, Arsenic trioxide is widely used in the treatment of malignant tumors such as acute promyelocytic leukemia [3]. Meanwhile, it has been included in the clinical practice guidelines on 2020 [4]. However, the mechanism by which arsenic induces apoptosis of malignant tumor cells is still unclear.

Glycogen Synthase Kinase $3 \beta$ (GSK-3 $\beta$ ) is a constitutive multifunctional serine /threonine kinase that induces tumor cell apoptosis through the destruction of oncogene products by the proteasome destruction [5]. It was reported that Nerigoside induced apoptosis in colorectal cancer cells (HT29, SW620) by inhibiting the ERK/GSK-3 $\beta / \beta$-catenin signaling pathway [6]. Moreover, GSK-3 $\beta$ is closely related to the function of the mitochondrial apoptotic pathway. It promotes the loss rate of mitochondrial membrane potential and the release of cytochrome $\mathrm{C}$ [7], which may be related to the regulation of Mcl-1 (myeloid cell leukemia-1) protein degradation [8]. These results suggest that the GSK-3 $\beta$-mediated mitochondrial apoptosis pathway plays an important role in the apoptosis of tumor cells.

62 GSK-3 $\beta$ can be regulated by a variety of signaling pathways to mediate mitochondrial activity, including PI3K/Akt, PKA, ERK, etc. [8]. GSK-3 $\beta$, as a 
downstream target protein of Akt, participates in the PI3K/Akt signaling pathway to regulate various biological processes such as cell cycle [9], cell proliferation, and apoptosis [10,11]. In addition, Gao Y H demonstrated that Akt inhibitors on gastric cancer cells (SGC-7901) can significantly reduce the expression of GSK-3 $\beta$, and increase the apoptotic family of enzymes (Bax, Bak, and caspase-3) [12]. In summary, PI3K/Akt regulate the expression of GSK-3 $\beta$ and induce tumor apoptosis.

In recent years, many studies have focused on the mechanism of GSK-3 $\beta$ in arsenic-induced tumor cell apoptosis, along with many controversies about the regulatory effect of arsenic on GSK-3 $\beta$. Wang, R. [13] demonstrated that the expression of p-GSK-3 $\beta$ was decreased in the apoptosis of acute myeloid leukemia cells (NB4, HL-60) induced by $\mathrm{As}_{2} \mathrm{O}_{3}(\mathrm{P}<0.05)$. On the contrary, Lo, Rico K.H. [14] found that the expression of p-GSK-3 $\beta$ in the arsenic intervention group was higher than the control group $(\mathrm{P}<0.05)$, which induced MCL cells apoptosis (Jeko-1, Granta-519). For wild-type myelogenous leukemia cells (U937- $\Delta$ C NDRG2) [15], there were no significant difference in GSK-3 $\beta$ and Mcl-1 protein expression between the $\mathrm{As}_{2} \mathrm{O}_{3}$ group and the control group $(\mathrm{P}>0.05)$. Nowadays, the regulation of arsenic on GSK-3 $\beta$ is still unclear, and the systematic reviews of the relationship between arsenic and GSK-3 $\beta$ have not been reported. To clarify the mechanism of GSK-3 $\beta$ in arsenic-induced apoptosis of tumor cells, we used meta-analysis of the literature on this topic, and took advantage of existing evidence to illustrate the mechanism of GSK-3 $\beta$ in arsenic-induced cancer cells apoptosis, so as to provide a theoretical basis for elucidating the mechanism of arsenic tumor-inhibiting activity. 


\section{Materials and methods}

\section{Inclusion criteria}

In this study, the inclusion criteria were formulated according to the principles of PICO;

Research design: 1) Experimental research published in Chinese and English. 2)

Research object (P): malignant tumor cells. 3) Intervention (I): The experimental group was exposed to arsenic or arsenic compounds. If there were time or dose-effect models related to arsenic and GSK-3 $\beta$ and PI3K/Akt in the study, we selected one group for analysis in each of the high-dose and low-dose group or the acute and subchronic toxicity test. 4) Control (C): Blank control group without any intervention measures. 5) Outcome (O): Apoptosis-related indicators (caspase-3, caspase-9, Bax, Bak, PARP, p-PARP) and GSK-3 $\beta$, p-GSK-3 $\beta$, Akt, p-Akt, Mcl-1.

\section{Exclusion criteria}

1) Non-Chinese or non-English papers. 2)The title or abstract of the paper does not contain arsenic or arsenic compounds and GSK-3 $\beta$. 3) The literature does not contain clear apoptotic indicators (the rate of apoptotic or changes in apoptosis-related indicators). 4) Repeated publication (published in both Chinese and English journals at the same time, the same author publishes similar articles in different magazines or the same data in articles published by the same author). 5) The data of the article is incomplete (lack of internal reference protein, the dose or time of arsenic poisoning is not clear). 6) The literature data cannot be extracted (the expression of GSK-3 $\beta$ or 
p-GSK-3 $\beta$ protein cannot be extracted). 7) Review articles, conference papers, or articles where only abstracts can be retrieved. 8) No control groups.

\section{Search strategy}

The literature included in this study came from PubMed, Web of Science, Cochrane Library, Excerpta Medica database (EMBASE), China National Knowledge Infrastructure (CNKI), Wan Fang Data databases, Wiper databases, and China Biology Medicine disc (CBMdisc). Keywords for this search included: arsenic, arsenite, $\mathrm{ATO}, \mathrm{As}_{2} \mathrm{O}_{3}, \mathrm{NaAsO}_{2}$, Arsenic trioxide, GSK-3 $\beta$, Glycogen Synthase Kinase 3 beta, apoptosis, caspase-3, caspase-9, Bax, Bcl-2, Mcl-1, Cyt-C, PARP, Akt, and P-Akt.

Taking PubMed database as an example:(((((()arsenic) OR As) OR ATO) OR

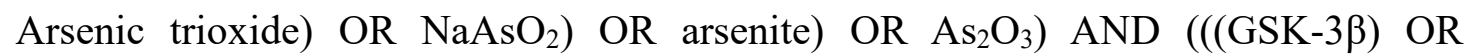
Glycogen Synthase Kinase 3 beta) OR Glycogen Synthase Kinase 3ß) AND ((((((((((apoptosis) OR caspase-3) OR caspase-9) OR Bax) OR Bcl-2) OR Mcl-1) OR Cyt-C) OR PARP) OR Akt) OR p-Akt).

\section{Search results}

In this study, 265 articles were retrieved from 8 databases. According to the inclusion and exclusion criteria, 19 papers were finally included and screened by two different researchers. According to the PICO principle, a total of 265 articles were included. There were 91 duplicate articles (same articles were retrieved in different databases), 11 conference papers, 1 review, and 1 non-Chinese non-English document. 
All of them were excluded and the remaining 158 articles were left. Taking the title and abstract into perspective, 118 articles and 2 additional articles (not containing arsenic and GSK-3 $\beta$ ), and 15 articles (not related to apoptosis) were eliminated. After studying the full text and through re-screening the remaining 23 articles, 4 articles with incomplete or undesirable data were eliminated, and finally, 19 articles were included. The search deadline was October 31, 2020. The search results are shown in Fig. 1.

\section{Quality evaluation}

This study made use of the Cochrane risk Migration assessment tool to systematically evaluate seven aspects for the 19 included articles.

1) Random sequence generation (selection bias). 2) Allocation concealment (selection bias)). 3) Blinding of participants and personnel (performance bias). 4) Blinding of outcome assessment (measurement bias). 5) incomplete outcome data (attrition bias). 6) Selective reporting (reporting bias). 7) Other sources of bias (other bias).

\section{Data collection}

The data of this study was collected by two reviewers independently. The collected data were cross-checked. If the literature with inconsistent results or trends is encountered, the two reviewers independently re-extracted the data from the article. The literature was included and summarized according to the following information:

1) Title of the paper, lead author, publication date. 2) Research object characteristics: 
cell line. 3) Intervention: type of arsenic, dose, exposure time. 4) Baseline data: site, number of groups (n), related proteins (mean, standard deviation (SD)).

\section{Data analysis}

The purpose of this study was to explore the effects of arsenic on Akt, GSK-3 $\beta$, caspase-3, caspase-9, Bax, Bcl-2, Mcl-1, Cyt-C, PARP, and to further explore the mechanism of GSK-3 $\beta$ apoptosis induced by arsenic.

The data analysis was performed by Review Manager 5.3 (The Nordic Cochrane Centre, The Cochrane Collaboration 2012, Portland, OR, USA) and Stata 12.0 (Stata Corp LP, College Station, TX, USA). Review Manager 5.3 software was used to evaluate the quality of the included literature according to the Cochrane risk deviation assessment tool. The apoptosis-related outcome indicators were continuous variables in this study. Taking into account the different units or large mean data included in the literature, the standardized mean difference (SMD) was used to reflect their effect size. The SMD formula used is: $\mathrm{d}_{i}=\frac{\overline{x_{1 i}}+\overline{x_{2 i}}}{S e} \quad(\mathrm{i}=1,2,3 \ldots \mathrm{k})$ In this study, the combined effect of each indicator in the experimental group and control group was described by standardized mean difference (SMD) and its $95 \%$ confidence interval. SMD and its confidence interval were observed by drawing a forest map. If $\mathrm{P}>0.05$ and the confidence interval contained 0 , it could not be considered a difference between the experimental and control group. If $\mathrm{P}<0.05$ and the confidence interval did not contain 0 , it indicates a statistical difference between the experimental and control group. Heterogeneity is assessed by calculating $I^{2}$. 
According to the Higgins JP T study [16], 25\%, 50\%, and $75 \%$ of $I^{2}$ were defined as low, medium, and high levels. The choice of the model was determined by observing the $\mathrm{P}$-value and $I^{2}$. When $\mathrm{P}<0.05$ and $I^{2}>50 \%$, the random effect model was selected; when $\mathrm{P}>0.05$ and $I^{2} \leq 50 \%$, the fixed effect model was chosen. Heterogeneity in the study was explained by $I^{2}$. In this study, the subgroup analysis was used to find the sources of heterogeneity in the included 19 articles. Exposure dose $(\leq 5 \mu \mathrm{mol} / \mathrm{L}$ or $>5$ $\mu \mathrm{mol} / \mathrm{L}$ ), exposure time ( $\leq 24 \mathrm{~h}$ or $>24 \mathrm{~h})$, and the GSK-3 site (Ser9 or non-Ser9) were used to determine the subgroups. Hence, GSK-3 $\beta$ was divided into two subgroups (Ser9 or non-Ser9) in the subgroup analysis of GSK-3 $\beta$ sites.

Meanwhile, R 4.0.1 software was used to establish a dose-effect model of arsenic to observe the dose-effect relationship of GSK-3 $\beta$ and Akt during the process of arsenic-induced apoptosis. The funnel chart was drawn by Review Manager 5.3 software to evaluate publication deviation. Stata 12.0 software was used for sensitivity analysis to evaluate the stability and reliability of the results. Chi-square test used $\alpha=0.05$ as the significance level; all statistical analyses are carried out on both sides. When $\mathrm{P}<0.05$, the difference was considered to be statistically significant.

\section{Results}

\section{The basic characteristics of included research}

A total of 19 articles were included in this study, including GSK-3 $\beta$ site, arsenic type, dose, time, and other information, as shown in Table 1. The experimental group was treated with different types of arsenic, including 14 arsenic trioxide $\left(\mathrm{As}_{2} \mathrm{O}_{3}\right), 3$ 
arsenic sulfide $\left(\mathrm{As}_{2} \mathrm{~S}_{3}\right)$, and 2 sodium arsenite $\left(\mathrm{NaAsO}_{2}\right)$.

The arsenic exposure dose was divided into a low-dose group $(\leq 5 \mu \mathrm{mol} / \mathrm{L}, \mathrm{n}=8)$ and a high-dose group $(>5 \mu \mathrm{mol} / \mathrm{L}, \mathrm{n}=11)$. The exposure time was divided into acute exposure group ( $\leq 24 \mathrm{~h}, \mathrm{n}=17)$ and subchronic exposure group ( $>24 \mathrm{~h}, \mathrm{n}=2)$. According to the position of arsenic on GSK-3 $\beta$, it was divided into Ser9 group ( $n=10)$ and non-Ser9 group $(n=8)$. The result variables were GSK-3 $\beta$ signaling pathway

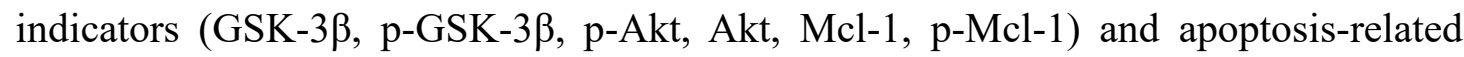
indicators (13 indicators included).

\section{Quality Evaluation}

The literature quality evaluation of the 19 documents, followed by the inclusion and exclusion criteria, found that the low-risk bias rate was greater than $75 \%$, and the high-bias risk rate was less than $10 \%$, as shown in the literature quality evaluation (Fig. 2A).

\section{The effect of arsenic on tumor cell apoptosis-related proteins}

The expression of apoptosis-related indicators was increased in the arsenic intervention group. The apoptosis-related protein cleaved-caspase-3 (SMD= 7.48, 95\% CI $(3.35,11.62))$, cleaved-caspase-9 $(\mathrm{SMD}=7.94,95 \%$ CI $(0.48,15.40))$, Bax $(\mathrm{SMD}=2.87,95 \% \mathrm{CI}(0.26,5.49)), \mathrm{p}-\mathrm{PARP}(\mathrm{SMD}=30.29,95 \% \mathrm{CI}(16.73,43.85))$ were increased, and the protein expression of pro-caspase 3 was decreased $(\mathrm{P}=0.002)$, while the expression of Bcl-2 and PARP were not statistically significant $(\mathrm{P}>0.05$, respectively; Fig.2B). Bak $(\mathrm{SMD}=-2.10,95 \% \mathrm{CI}(-3.83,-0.38))$ and $\mathrm{Mcl}-1(\mathrm{SMD}=$ 
$-2.25,95 \% \mathrm{CI}(-4.16,-0.33))$ were decreased in the arsenic-exposed group (Fig. 2C), the expression of cytochrome $\mathrm{C}$ in the cytoplasm increased $(\mathrm{SMD}=18.59,95 \% \mathrm{CI}$ (7.50,29.69)), while the cytochrome $\mathrm{C}$ in the mitochondria $(\mathrm{SMD}=-10.70,95 \% \mathrm{CI}$ $(-18.35,-3.05))$ were decreased (Fig. 2D).

\section{The effect of arsenic on the expression of GSK-3 $\beta$ protein in tumor cells}

In the meta-analysis of arsenic on GSK-3 $\beta$, the expression level of GSK-3 $\beta$ in the arsenic-exposed group was lower than the control group ( $\mathrm{SMD}=-0.92,95 \% \mathrm{CI}(-1.78$, -0.06); Fig. 3A), and there was no statistically significant difference in the expression of $\mathrm{p}-\mathrm{GSK}-3 \beta(\mathrm{P}>0.05$; Fig. 3B $)$.

\section{The effects of arsenic on GSK-3ß proteins in tumor cells}

Compared to the control group, the expression of GSK-3 $\beta$ (Ser9) was decreased in the arsenic intervention group $(\mathrm{SMD}=-1.61,95 \% \mathrm{CI}(-2.68,-0.55)$; Fig. 3C). The downstream apoptosis-related indicators of GSK-3 $\beta$ (Ser9) in the meta-analysis, the loss rate of mitochondrial membrane potential, the expression of cleaved-caspase 3 and cleaved-caspase-9 in the arsenic intervention group were increased, while the expression of pro-caspase- 3 and pro-caspase-9 were decreased $(\mathrm{P}<0.05$, respectively; Fig. 3D).

\section{The effect of arsenic on Akt-related proteins between tumor cells}

The results of Figure 4 showed that there was no significant difference in the expression of Akt in the arsenic exposure group (Fig. 4A), while the expression of p-Akt was decreased $(\mathrm{SMD}=-5.46,95 \% \mathrm{CI}(-8.67,2.24)$; Fig. 4B) 
The literature containing arsenic and Akt agonists were extracted from the 19

235 articles. Meanwhile, the arsenic exposed group was used as the control group, and the

236 combined treatment with arsenic and Akt agonist was used as the experimental group.

237 Compared with the control group (arsenic-exposed group), the expression of GSK-3 $\beta$

238 in the combined treatment group with arsenic and Akt agonist was not statistically

239 different $(\mathrm{P}>0.05$; Fig. $4 \mathrm{C})$, while the expression of $\mathrm{p}-\mathrm{GSK}-3 \beta$ was decreased $(\mathrm{SMD}=$ $240 \quad-2.94,95 \%$ CI (-5.47, -0.41); Fig. 4D).

241 At the same time, we also included four additional pieces of literature with no 242 arsenic intervention, taking the Akt inhibitor group as the experimental group, and the 243 control group with no other treatment measures. The expression of p-GSK-3 $\beta$ in the 244 experimental group was lower than that of the control group $(\mathrm{SMD}=-6.36,95 \% \mathrm{CI}$ 245 (-8.94,-3.79); Fig. 4E).

\section{Subgroup analysis of arsenic exposure dose}

The results of subgroup analysis showed that the expression of GSK-3 $\beta$ (Ser9) and pro-caspase-3 in the high-dose and low-dose arsenic intervention groups were decreased, and the expression of $\mathrm{Bax}$ and $\Delta \psi \mathrm{M}$ loss rate increased $(\mathrm{P}<0.05$,

250 respectively). After a low-dose arsenic intervention, the expression of p-Akt was 251 decreased $(\mathrm{SMD}=-4.17,95 \%$ CI $(-6.77,-1.57))$, while the expression of cleaved252 caspase-3 increased in the high-dose arsenic-exposed group $(\mathrm{SMD}=12.70,95 \% \mathrm{CI}$

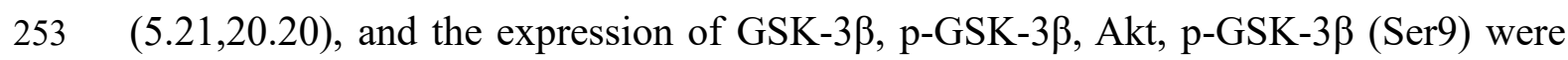


not statistically different $(\mathrm{P}>0.05$, respectively; Fig. 5A)

\section{Subgroup analysis of arsenic exposure time}

There was no significant difference in the expression of GSK-3 $\beta$, p-GSK-3 $\beta$, and Akt in the acute exposure group ( $\leq 24 \mathrm{~h})$ and subchronic exposure group $(>24 \mathrm{~h})$. The expression of p-Akt, GSK-3 $\beta$ (Ser9) and p-GSK-3 (Ser9) were having no significant differences in the acute arsenic exposure group $(\mathrm{P}>0.05)$, while the expression of p-Akt was decreased after the subchronic arsenic intervention $(\mathrm{SMD}=-8.99,95 \% \mathrm{CI}$ $=(-14.29,-3.68) ;$ Fig. 5B).

\section{Subgroup analysis of GSK-3ß sites exposed to arsenic}

Compared with the control group, the expression of GSK-3 $\beta$ (ser9), p-Akt, Mcl-1, pro-caspase-3, $\Delta \psi \mathrm{M}$ loss rate, and cleaved-caspase-3 were decreased in the arsenic intervention group $(\mathrm{P}<0.05$, respectively), while the expression of $\mathrm{p}$-GSK-3 $\beta$, Akt were not significantly different $(\mathrm{P}>0.05$, respectively; Fig. 5C).

\section{Dose effect analysis of arsenic and GSK-3ß}

In this study, the Spline model was used to explore the effect of the dose of arsenic on GSK-3 $\beta$, p-GSK-3 $\beta$, Akt, and p-Akt (Fig. 6). The results showed that the content of p-GSK-3 $\beta$ was increased with the arsenic exposure dose when the dose of arsenic was less than $8 \mu \mathrm{mol} / \mathrm{L}$. It had also shown a downward trend when the dose of arsenic was more than $8 \mu \mathrm{mol} / \mathrm{L}$ (Fig. 6B). In the dose-effect analysis of arsenic and Akt, as the dose of arsenic was less than $9 \mu \mathrm{mol} / \mathrm{L}$, the expression of $\mathrm{p}$-Akt showed a decreasing trend. The content of p-Akt decreased with the increase in the arsenic exposure dose when the dose of arsenic was more than $9 \mu \mathrm{mol} / \mathrm{L}$ (Fig. 6D). There was 
no dose-effect relationship between GSK-3 $\beta$ and Akt (Fig. 6A and C).

277

\section{Sensitivity analysis}

Taking the sensitivity analysis of arsenic and GSK-3 $\beta$ as an instance, the points of all results were distributed on both sides of the midline, and the results of 19 references did not exceed the midline with 95\% CI. After being excluded, the results did not change significantly, which revealed that the results of this study were relatively stable (Fig. 7A).

\section{Publication bias}

Taking arsenic and p-GSK-3 $\beta$ as an example to explore whether there is a publication bias, the funnel chart showed that the results of all the included literature were arranged symmetrically around the centerline, indicating that the publication offset was not significant (Fig. 7B).

\section{Discussion}

Arsenic can induce apoptosis of malignant tumor cells, as a consequence it has been used in the treatment of some cancers. As a key protein in multiple signaling pathways, GSK-3 $\beta$ plays a key role in tumor apoptosis. However, the mechanism of GSK-3 $\beta$ in arsenic-induced tumor cell apoptosis is contradictory. In this meta-analysis, we suggested that arsenic could inhibit the expression of p-Akt, inhibit GSK-3 $\beta$ (Ser9), down-regulate the expression of Mcl-1, and mediate the mitochondrial apoptosis pathway. The results of this study provided a theoretical basis for the molecular mechanism of arsenic inhibition on the tumor. 

induce tumor cell apoptosis. Zhen Tan et al. [18] showed that arsenic significantly

299 decreased the expression of Akt and GSK-3 $\beta$ on PC12 cells. This study found that 300 arsenic inhibited the expression of GSK-3 $\beta$, p-Akt, and Mcl-1 protein, thereby 301 inducing tumor cell apoptosis, and the combined treatment of arsenic and Akt agonist inhibited the expression of $\mathrm{p}-\mathrm{GSK}-3 \beta$. In addition, GSK-3 $\beta$ was regulated by multiple

303 pathways in arsenic-induced tumor cell apoptosis, and the mechanism might be related to cross-talk between various signaling pathways. In the apoptosis of myelogenous leukemia induced by arsenic trioxide [15], NDRG2, as a carrier between PP2A and GSK-3 $\beta$, promoted the dephosphorylation of GSK-3 $\beta$ and reduced the expression of its downstream Mcl-1 protein, and finally induced tumor cell apoptosis through mitochondrial apoptosis pathway (Fig. 8). Similarly, $\mathrm{As}_{2} \mathrm{O}_{3}$ induces acute promyelocytic leukemia (NB4) apoptosis by down-regulating the expression of IL-3R $\alpha$ and inhibiting PI3K/Akt signaling pathway. Meanwhile, the expression of 311 p-GSK-3 $\beta$ was significantly reduced [29], suggesting that arsenic might inhibit IL-3R $\alpha$ by GSK-3 $\beta$ (Fig. 8). Furthermore, arsenic could activate NF- $\kappa B$ [32] and IKK $\beta$ kinase [24], down-regulate the expression of GSK-3 $\beta$ (Fig. 8). The above results indicated that arsenic can regulate GSK-3 $\beta$ through a variety of ways, thereby

315 inducing apoptosis of malignant tumors. There are two sites for GSK-3 $\beta$ (Ser9 and Tyr-216). The subgroup analysis results showed that high-dose and low-dose arsenic could inhibit the expression of p-Akt, down-regulate GSK-3 $\beta$ (ser9), and ultimately 318 induced tumor cell apoptosis. 
GSK-3 $\beta$, which is closely related to mitochondrial function, can activate the apoptotic pathway of mitochondrial damage. In recent years, some studies have shown that GSK-3 $\beta$ participated in the opening of mitochondrial permeability transition pore (mPTP) and phosphorylation of GSK-3 $\beta$ at Ser9, could increase the threshold of mPTP opening. The results suggested that the loss rate of mitochondrial membrane potential was significantly increased in the arsenic-exposed group, which further confirmed this apoptosis pathway. GSK-3 $\beta$ participated in regulating glycogen synthesis, changing mitochondrial permeability, and promoting the release of cytochrome $\mathrm{C}$ in mitochondria [33]. At the same time, the study found that the expression of Mcl-1 in the arsenic treatment group was decreased, and the expression of Bax, Bak, and Caspase-3 was increased. It may be due to the phosphorylation of Bcl-2, triggering the Caspase cascade reaction [34], promoting the release of cytochrome $\mathrm{C}$ [25] induced by $\mathrm{As}_{2} \mathrm{O}_{3}$. It is suggested that arsenic may trigger the mitochondrial damage pathway through GSK-3 $\beta$.

However, there were several limitations in this study. Non-English and nonChinese literature was not included in the search, which might result in insufficient literature. At the same time, there were few pieces of literature involved in in-vivo experiments $(n=2)[35,36]$, which were not included in this study. p-GSK-3 $\beta$ had high heterogeneity in our research. Although we did subgroup analysis of time, dose and GSK-3 $\beta$ sites, it might also be affected by other factors such as arsenic type and cell line. Due to the number of included literature, the subgroup analysis of arsenic types and cell lines were not carried out in this study. In the sensitivity analysis, the stability 
341 of the included literature was sound. The points of all the results were distributed on

342 both sides of the midline, and the results did not change significantly after being

343 excluded. Based on the funnel chart, the results of the included literature were

344 arranged symmetrically around the centerline, and the publication bias was not 345 significant.

346 In summary, arsenic can inhibit the expression of PI3K/Akt and GSK-3 $\beta$ (Ser9), 347 down-regulate the expression of Mcl-1 protein, and trigger apoptosis mediated by the 348 mitochondrial pathway. The role of NDRG2, IL-3R $\alpha, \mathrm{NF}-\kappa \mathrm{B}$ and other molecular 349 relationships in the regulation of GSK-3 $\beta$ by arsenic should be further explored in the 350 future, to clarify the molecular mechanism of arsenic regulating GSK-3 3 .

351 Declarations

352 Ethics approval and consent to participate

353 Not applicable' for that section

354 Consent for publication

355 Not applicable.

356 Availability of data and materials

357 The datasets generated and/or analysed during the current study are available

358 from the corresponding author on reasonable request.

359 In this study, The datasets came from PubMed, Web of Science, Cochrane Library, 
360 Excerpta Medica database (EMBASE), China National Knowledge Infrastructure

361 (CNKI), Wan Fang Data databases, Wiper databases, and China Biology Medicine 362 disc (CBMdisc).

363 1) PubMed (https://pubmed.ncbi.nlm.nih.gov/), 2) EMBASE (https://www.embase. $364 \mathrm{com} /$ ), 3) Web of Science (http://isiknowledge.com/wos), 4) Cochrane Library 365 (https:// www.cochranelibrary.com/library), 5) CNKI (https://www.cnki.net/), 6) Wan 366 Fang Data databases (http://www.wanfangdata.com.cn/index.html), 7) Wiper 367 databases (http://www. cqvip.com), 8) CBMdisc (http://www.sinomed.ac.cn/)

\section{Competing interests}

369 The authors declare no conflicts of interest.

\section{$370 \quad$ Funding}

371 This work was supported by the National Natural Science Foundation of China 372 (No.81760584).

\section{Authors' contributions}

374 Xin Gao contributed significantly to analysis and manuscript preparation, 375 extract data from literatures, performed the data analyses and wrote the 376 manuscript;

377 Bin Deng and Shanshan Ran contributed to the conception of the study;

378 Shugang Li helped perform the analysis with constructive discussions. 
First of all, I would like to express my gratitude to Shugang Li-PhD for his instructive advice and useful suggestions on my thesis. Meanwhile, I am also very grateful to the teacher for giving me a help in translation research. Finally, I am indebted to my friends and parents for their support and encouragement.

\section{Reference}

1. Swindell EP, Hankins PL, Chen H, et al. Anticancer activity of small-molecule and nanoparticulate arsenic(III) complexes. Inorg Chem. 2013; 52:12292-12304.

2. Huang W, Zeng YC. A candidate for lung cancer treatment: arsenic trioxide. Clin Transl Oncol. 2019; 21:1115-1126.

3. Niu C, Yan H, Yu T, et al. Studies on treatment of acute promyelocytic leukemia with arsenic trioxide: remission induction, follow-up, and molecular monitoring in 11 newly diagnosed and 47 relapsed acute promyelocytic leukemia patients. Blood. 1999; 94:3315-3324 .

4. Heuser M, Ofran Y, Boissel N, et al. Acute myeloid leukaemia in adult patients: ESMO Clinical Practice Guidelines for diagnosis, treatment and follow-up. Ann Oncol. 2020.

5. Sahin I, Eturi A, De Souza A, et al. Glycogen synthase kinase-3 beta inhibitors as novel cancer treatments and modulators of antitumor immune responses. Cancer Biol Ther. 2019; 20:1047-1056.

6. Wen SY, Chen YY, Deng CM, et al. Nerigoside suppresses colorectal cancer cell growth and metastatic potential through inhibition of ERK/GSK3 $\beta / \beta$-catenin signaling pathway. Phytomedicine. 2019; 57:352-363.

7. Linseman DA, Butts BD, Precht TA, et al. Glycogen synthase kinase-3beta 
phosphorylates Bax and promotes its mitochondrial localization during neuronal apoptosis. J Neurosci. 2004; 24:9993-10002.

8. Yang K, Chen Z, Gao J, et al. The Key Roles of GSK-3 $\beta$ in Regulating Mitochondrial Activity. Cell Physiol Biochem. 2017; 44:1445-1459.

9. Liang J, Slingerland JM. Multiple roles of the PI3K/PKB (Akt) pathway in cell cycle progression. Cell Cycle. 2003; 2:339-345.

10. Deng S, Dai G, Chen S, et al. Dexamethasone induces osteoblast apoptosis through ROS-PI3K/AKT/GSK3 $\beta$ signaling pathway. Biomed Pharmacother. 2019; 110: 602-608.

11. Xie Y, Shi $\mathrm{X}$, Sheng $\mathrm{K}$, et al. PI3K/Akt signaling transduction pathway, erythropoiesis and glycolysis in hypoxia. Mol Med Rep. 2019; 19:783-791.

12. Gao YH, Zhang HP, Yang SM, et al. Inactivation of Akt by arsenic trioxide induces cell death via mitochondrial-mediated apoptotic signaling in SGC-7901 human gastric cancer cells. Oncol Rep. 2014; 31:1645-1652.

13. Wang R, Xia L, Gabrilove J, et al. Downregulation of Mcl-1 through GSK-3 $\beta$ activation contributes to arsenic trioxide-induced apoptosis in acute myeloid leukemia cells. Leukemia. 2013; 27:315-324.

14. Lo RK, Kwong YL. Arsenic trioxide suppressed mantle cell lymphoma by downregulation of cyclin D1. Ann Hematol. 2014; 93:255-265.

15. Park S, Han HT, Oh S S, et al. NDRG2 Sensitizes Myeloid Leukemia to Arsenic Trioxide via GSK3ß-NDRG2-PP2A Complex Formation. Cells. 2019; 8.

16. Higgins JP, Thompson SG, Deeks JJ, et al. Measuring inconsistency in meta-analyses. BMJ. 2003; 327:557-560.

17. Huang HS, Liu ZM, Cheng YL. Involvement of glycogen synthase kinase-3 $\beta$ in arsenic trioxide-induced p21 expression. Toxicol Sci. 2011; 121:101-109.

18. Tan Z, Kang T, Zhang X, et al. Nerve growth factor prevents arsenic-induced 
toxicity in PC12 cells through the AKT/GSK-3ß/NFAT pathway. J Cell Physiol. $2019 ; 234: 4726-4738$.

19. Deng Lijun, Lv Yuling, Wu Dan. Ginsenoside Rb1 inhibits arsenic sulfide-induced neuronal PC12 toxicity through the AKT/GSK-3ß/NFAT pathway. Chinese Journal of Arteriosclerosis. 2019; 27:667-673.

20. Zhai B, Jiang $\mathrm{X}, \mathrm{He} \mathrm{C}$, et al. Arsenic trioxide potentiates the anti-cancer activities of sorafenib against hepatocellular carcinoma by inhibiting Akt activation. Tumour Biol. 2015; 36: 2323-2334.

21. Wang R, Li Y, Gong P, et al. Arsenic Trioxide and Sorafenib Induce Synthetic Lethality of FLT3-ITD Acute Myeloid Leukemia Cells. Mol Cancer Ther. 2018; 17: 1871-1880.

22. Hossain K, Akhand AA, Kawamoto Y, et al. Caspase activation is accelerated by the inhibition of arsenite-induced, membrane rafts-dependent Akt activation. Free Radic Biol Med. 2003; 34:598-606.

23. Zheng L, Jiang H, Zhang ZW, et al. Arsenic trioxide inhibits viability and induces apoptosis through reactivating the Wnt inhibitor secreted frizzled related protein-1 in prostate cancer cells. Onco Targets Ther. 2016; 9:885-894.

24. Guo W, Liu J, Jian J, et al. IKK- $\beta / \mathrm{NF}-\kappa \mathrm{B}$ p65 mediates p27(Kip1) protein degradation in arsenite response. Biochem Biophys Res Commun. 2014; 447:563-568.

25. Watcharasit P, Thiantanawat A, Satayavivad J. GSK3 promotes arsenite-induced apoptosis via facilitation of mitochondria disruption. J Appl Toxicol. 2008; 28: 466-474.

26. You Peidong. Mcl-1 gene plays an important role in HHT and ATO to significantly kill HL60 cells co-cultured with bone marrow stromal HS-5 cells. Fujian Medical University. 2017. 
27. Chen $\mathrm{P}$, Zhan W, Wang B, et al. Homoharringtonine potentiates the antileukemic activity of arsenic trioxide against acute myeloid leukemia cells. Exp Cell Res. 2019; 376:114-123.

28. Chen Y J, Huang C H, Shi Y J, et al. The suppressive effect of arsenic trioxide on TET2-FOXP3-Lyn-Akt axis-modulated MCL1 expression induces apoptosis in human leukemia cells. Toxicol Appl Pharmacol. 2018; 358:43-55.

29. Chen P, Wu JY, Huang H F, et al. The effect to IL-3Ralpha, downstream PI3k/Akt signaling of all-trans retinoic acid and arsenic trioxide in NB4 cells. Pharmazie. 2014; 69:297-300.

30. Huang CH, Lee YC, Chiou JT, et al. Arsenic trioxide-induced p38 MAPK and Akt mediated MCL1 downregulation causes apoptosis of BCR-ABL1-positive leukemia cells. Toxicol Appl Pharmacol. 2020; 397:115013.

31. Jin Qing. HHT combined with $\mathrm{As}_{2} \mathrm{O}_{3}$ can synergistically kill U937 cells co-cultured with bone marrow stromal HS-5 cells and its mechanism. Fujian Medical University. 2016.

32. Zhong L, Xu F, Chen F. Arsenic trioxide induces the apoptosis and decreases NF-кB expression in lymphoma cell lines. Oncol Lett. 2018; 16:6267-6274.

33. Vidri RJ, Fitzgerald TL. GSK-3: An important kinase in colon and pancreatic cancers. Biochim Biophys Acta Mol Cell Res. 2020; 1867:118626.

34. Li Dan, Song Tingting, Liu Weihua,et al. Research progress on arsenic trioxide-induced apoptosis in mitochondrial pathways. China Contemporary Medicine. 2015; 22:21-25.

35. Zhai B, Jiang $\mathrm{X}, \mathrm{He} \mathrm{C}$, et al. Arsenic trioxide potentiates the anti-cancer activities of sorafenib against hepatocellular carcinoma by inhibiting Akt activation. Tumour Biol. 2015; 36:2323-2334.

36. Miltonprabu S, Sumedha NC, Senthilraja P. Diallyl trisulfide. a garlic polysulfide 
protects against As-induced renal oxidative nephrotoxicity, apoptosis and 482 inflammation in rats by activating the Nrf2/ARE signaling pathway. Int Immunopharmacol. 2017; 50:107-120. 
265 articles obtained by database serarch $(n=246)$ :Pubmed $(n=23)$,

Web of science $(\mathrm{n}=28)$, Embase $(\mathrm{n}=32)$, Cochrane Library

$(\mathrm{n}=0)$, CNKI $(\mathrm{n}=3)$, Wan Fang $(\mathrm{n}=156)$, Viper $(\mathrm{n}=4)$, SinMed $(\mathrm{n}=19)$

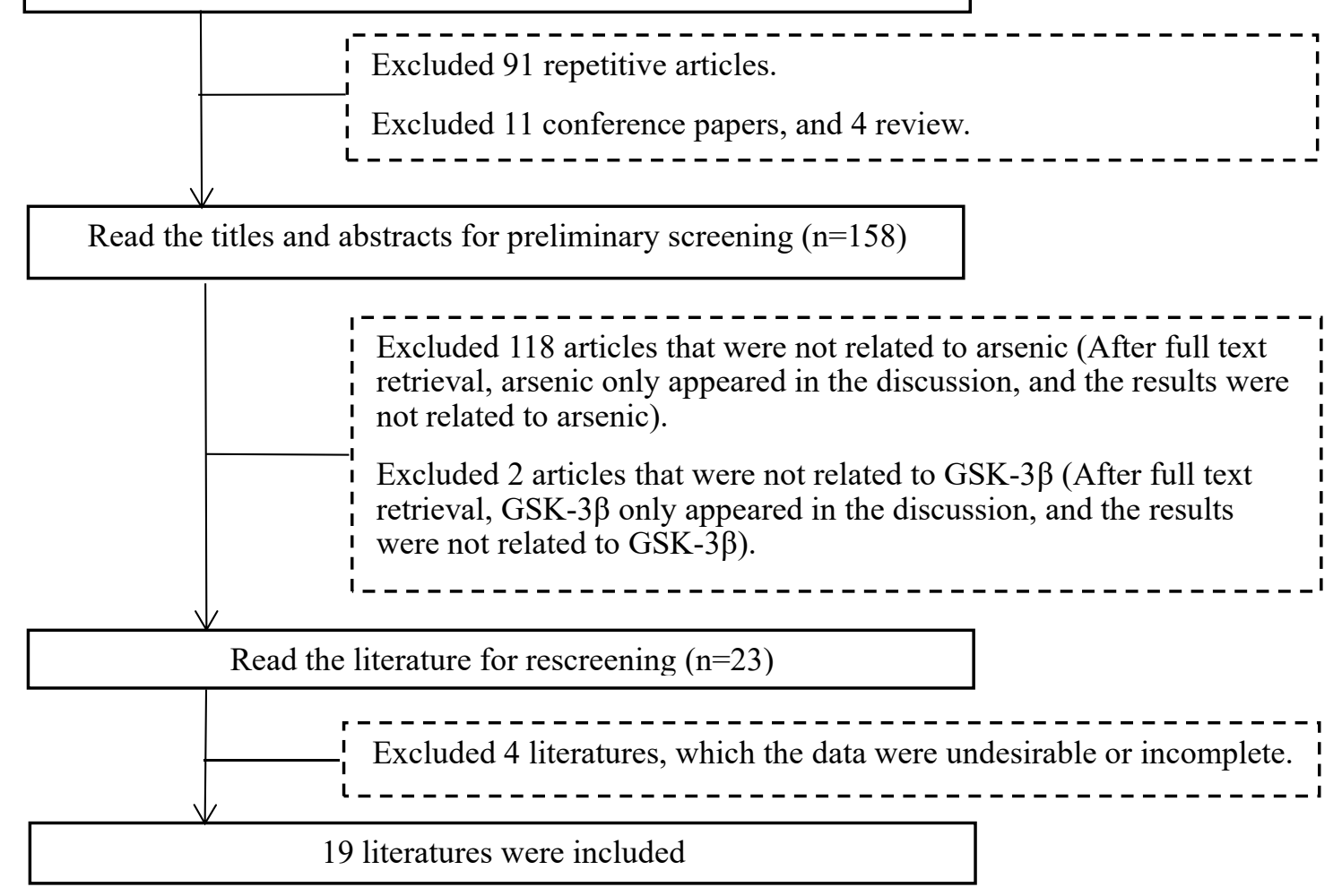

Figure 1. The flow chart for determining the final literature included in the meta-analysis 


\begin{tabular}{|c|c|c|c|c|c|c|c|c|c|}
\hline Authors & Site & Year & Language & $\mathrm{N}$ & Arsenic & Dose & Time & Outcome & Cell line \\
\hline Huang,Huei-Sheng et al. ${ }^{[17]}$ & ser9 & 2011 & English & 3 & $\mathrm{As}_{2} \mathrm{O}_{3}$ & $>5$ & $\leq 24$ & $1,2,3$ & $\mathrm{~A} 431, \mathrm{HaCaT}$ \\
\hline Tan,Zhen et al. ${ }^{[18]}$ & ser9 & 2019 & English & 3 & $\mathrm{As}_{2} \mathrm{~S}_{3}$ & $>5$ & $\leq 24$ & $1,2,3,5,6,7,8,9,10$ & $\mathrm{PC} 12$ \\
\hline Deng, L.J. et al ${ }^{[19]}$ & Total & 2019 & Chinese & 3 & $\mathrm{As}_{2} \mathrm{~S}_{3}$ & $>5$ & $\leq 24$ & $1,2,3,5,6,9$ & $\mathrm{PC} 12$ \\
\hline Zhai, B. et al. ${ }^{[20]}$ & Total & 2015 & English & 3 & $\mathrm{As}_{2} \mathrm{O}_{3}$ & $\leq 5$ & $>24$ & $1,2,3,5$ & HepG2,HUH7 \\
\hline Lo, Rico K. H. et al. ${ }^{[14]}$ & Tyr-216 & 2014 & English & 3 & $\mathrm{As}_{2} \mathrm{O}_{3}$ & $\leq 5$ & $\leq 24$ & 1,3 & Jeko-1,Granta-519 \\
\hline Gao,Y.H. et al. ${ }^{[12]}$ & ser9 & 2014 & English & 3 & $\mathrm{As}_{2} \mathrm{O}_{3}$ & $\leq 5,>5$ & $\leq 24$ & $1,2,3,4,5,6,8,11$ & SGC-7901 \\
\hline Wang,Rui et al. ${ }^{[21]}$ & ser9 & 2018 & English & 3 & $\mathrm{As}_{2} \mathrm{O}_{3}$ & $\leq 5$ & $\leq 24$ & $1,2,5,6,12,13$ & MOLM13 \\
\hline Hossain, K. et al. ${ }^{[22]}$ & Total & 2003 & English & 3 & $\mathrm{NaAsO}_{2}$ & $>5$ & $\leq 24$ & 1 & Jurkat \\
\hline Zheng,Lei et al. ${ }^{[23]}$ & ser9 & 2016 & English & 3 & $\mathrm{As}_{2} \mathrm{O}_{3}$ & $\leq 5,>5$ & $\leq 24$ & 1 & LncaP,PC3 \\
\hline Guo, Wei et al. ${ }^{[24]}$ & Total & 2014 & English & 3 & $\mathrm{NaAsO}_{2}$ & $>5$ & $\leq 24$ & 1 & MEFs \\
\hline Wang, R. et al. ${ }^{[13]}$ & $\operatorname{ser} 9$ & 2013 & English & 3 & $\mathrm{As}_{2} \mathrm{O}_{3}$ & $\leq 5$ & $\leq 24$ & $1,2,5,12,14$ & NB4,HL-60 \\
\hline Watcharasit, Piyajit et al. ${ }^{[25]}$ & ser9 & 2008 & English & 4 & $\mathrm{As}_{2} \mathrm{~S}_{3}$ & $>5$ & $\leq 24$ & $1,2,3,5,6$ & SH-SY5Y \\
\hline You, P.D. et al. ${ }^{[26]}$ & Total & 2017 & Chinese & 3 & $\mathrm{As}_{2} \mathrm{O}_{3}$ & $>5$ & $\leq 24$ & $1,2,3,4,5,12$ & HL-60 \\
\hline Park,S. et al. ${ }^{[15]}$ & ser9 & 2019 & English & 3 & $\mathrm{As}_{2} \mathrm{O}_{3}$ & $\leq 5$ & $\leq 24$ & $1,2,3,5,6,11,12$ & U937 \\
\hline Chen, P. et al. ${ }^{[27]}$ & Total & 2019 & English & 3 & $\mathrm{As}_{2} \mathrm{O}_{3}$ & $>5$ & $\leq 24$ & 1,12 & HL-60,U937 \\
\hline Chen, Y. J. et al. ${ }^{[28]}$ & ser9 & 2018 & English & 3 & $\mathrm{As}_{2} \mathrm{O}_{3}$ & $>5$ & $\leq 24$ & $1,2,3,4,5,6,7,8,11,12,13$ & U937 \\
\hline Chen, P. et al. ${ }^{[29]}$ & Total & 2014 & English & 3 & $\mathrm{As}_{2} \mathrm{O}_{3}$ & $\leq 5$ & $>24$ & 1,2 & U937 \\
\hline Huang, C. H. et al. ${ }^{[30]}$ & ser9 & 2020 & English & 3 & $\mathrm{As}_{2} \mathrm{O}_{3}$ & $>5$ & $\leq 24$ & $1,2,3,5,6,7,8,9,12,13$ & K562 \\
\hline Jin, $J$ et al. ${ }^{[31]}$ & Total & 2016 & Chinese & 3 & $\mathrm{As}_{2} \mathrm{O}_{3}$ & $>5$ & $\leq 24$ & $1,2,3,4,5,11,12$ & U937 \\
\hline
\end{tabular}

486 The number of parallel samples was represented by $n$ in the experimental group; GSK-3 $\beta$, serine/threonine kinase GSK-3, a

487 multifunctional kinase; Akt, is a serine/threonine kinase and it participates in the key role of the PI3K signaling pathway; MCL-1,

488 Myeloid cell leukemia-1, a member of antiapoptotic Bcl-2 family proteins, is a key regulator of mitochondrial homeostasis;

489 caspase-3, is an apoptotic cysteine protease, is the main executioner of apoptosis; caspase-9, is a key player in the intrinsic or

490 mitochondrial pathway; 1, GSK-3ß; 2, Akt; 3, caspase-3; 4, caspase-9; 5, Bcl-2; 6, Bax; 7, ROS; 8, $\Delta \psi \mathrm{M}$ loss rate; 9, Cyt C; 10 ,

491 C-MYC; 11, PARP; 12, Mcl-1; 13, Bak. 




$\mathrm{B}$

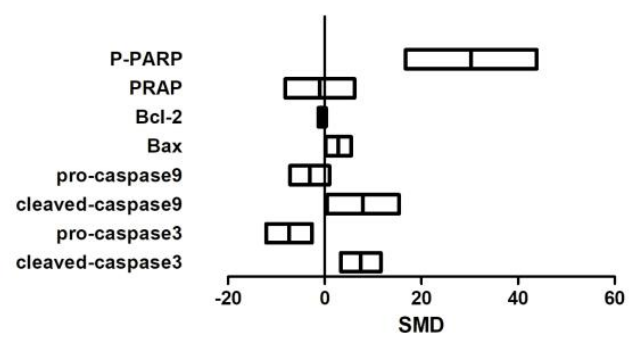

C

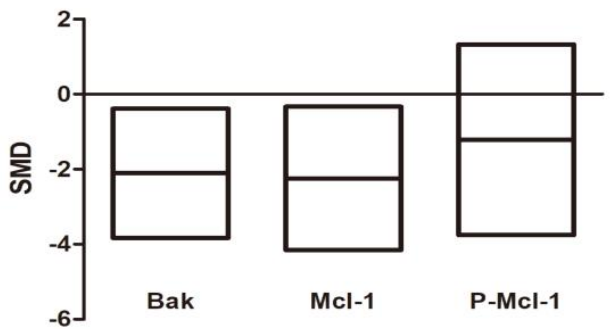

D

Figure 2. The effect of arsenic on apoptosis-related proteins. SMD, standardized mean difference; PARP, poly ADP-ribose

494 polymerase; caspase-3, cysteinyl aspartate specific proteinase-3; caspase -9, cysteinyl aspartate specific proteinase-9; Bcl-2,

B-cell lymphoma 2 ;,Bax, Bcl-2-associated X protein. Mcl-1, myeloid cell leukemia-1; Bak, Bak BH3 peptide complex; $\Delta \psi \mathrm{M}$, 
A
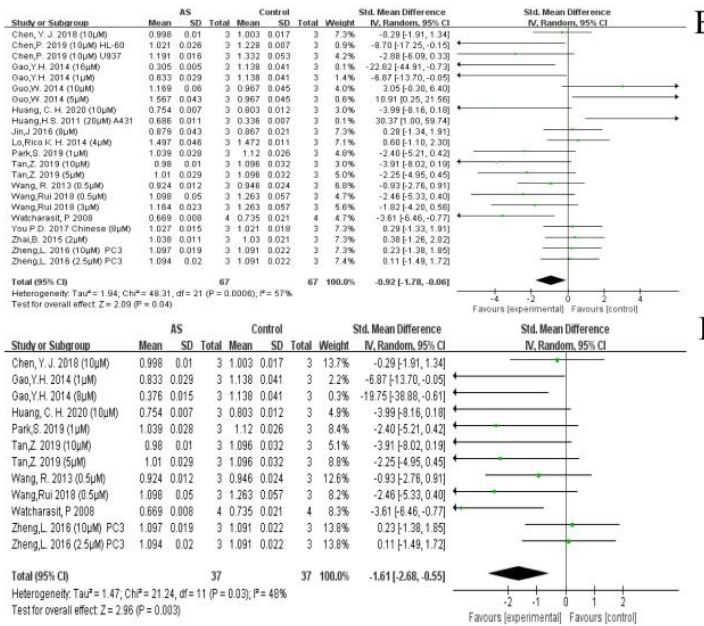

B

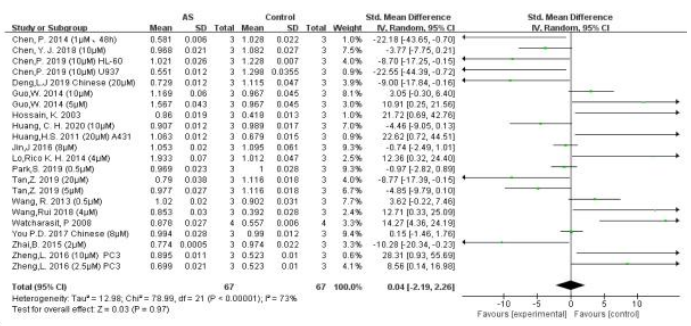

D

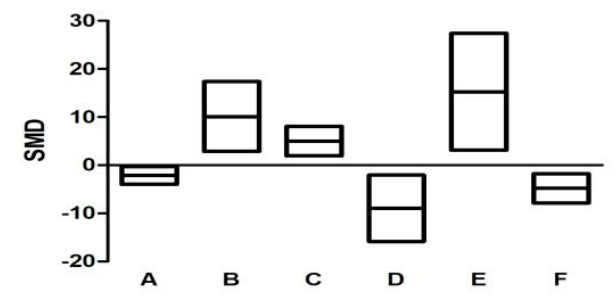

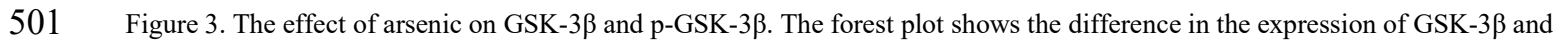

502 p-GSK-3 3 between the control group and the arsenic-exposed group. SMD, standardized mean difference; $95 \%$ CI, 95\%

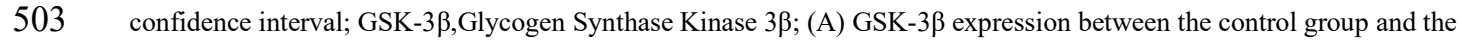
arsenic-exposed group. (B) The expression of p-GSK-3 $\beta$ between the control group and the arsenic-exposed group. (C) The loss rate; C, cleaved -caspase3; D, pro-caspase -3; E, cleaved-caspase-9; F, pro-caspase-9. 


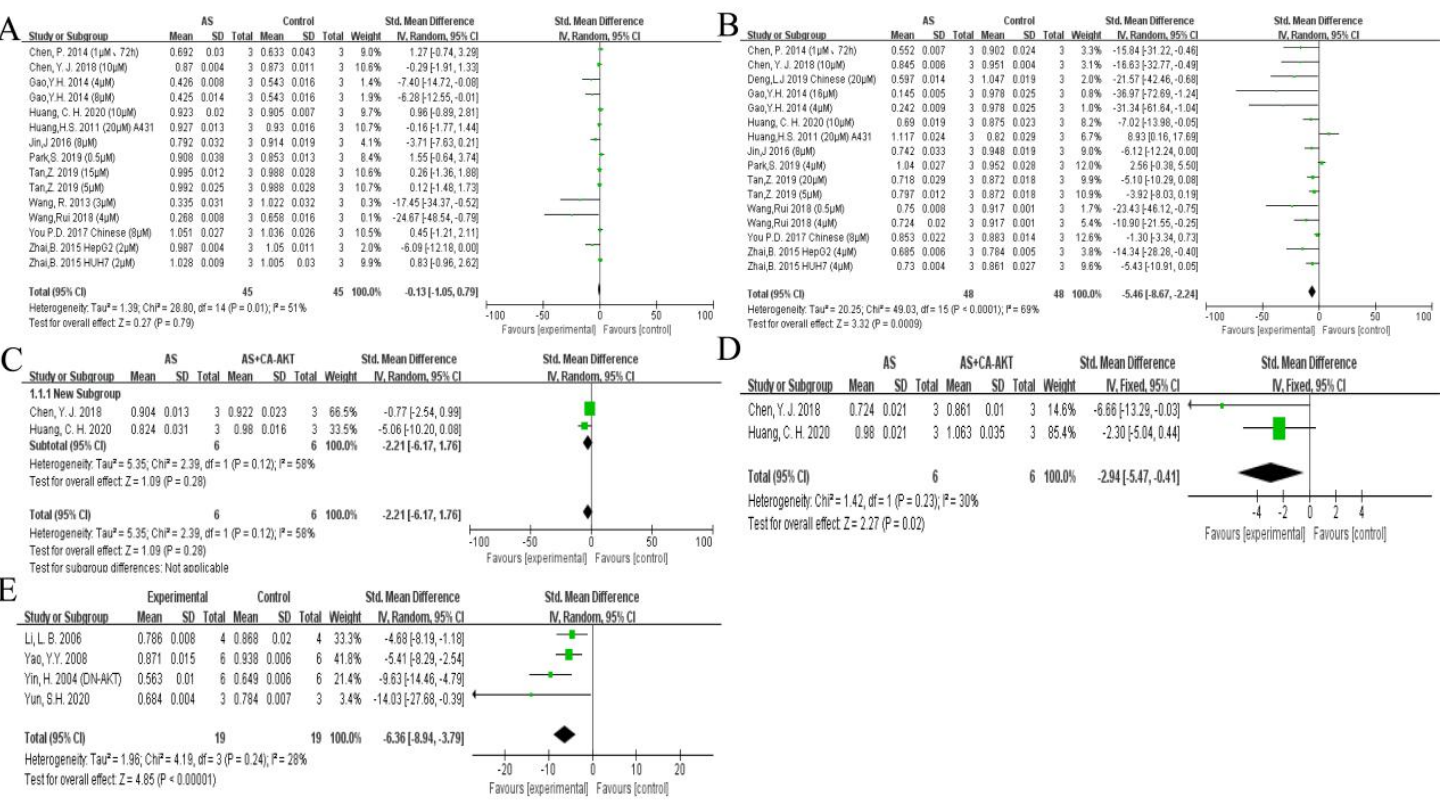

Figure 4. The effect of arsenic on Akt and p-Akt. The forest plot shows the difference between Akt and p-Akt expression between the control group and the arsenic-exposed group. SMD, standardized mean difference; 95\% CI, 95\% confidence interval; Akt,

510 protein kinase B; (A) the expression of Akt between the control group and the arsenic-exposed group. (B) the expression of

511 P-Akt between the control group and the arsenic-exposed group. (C) GSK-3 $\beta$ expression between the arsenic-exposed group and

512 the combined treatment group with arsenic and Akt agonist. (D) The expression of p-GSK-3 $\beta$ between the arsenic-exposed group

513 and the combined treatment group with arsenic and Akt agonist. (E) The forest plot shows the difference in GSK-3 $\beta$ expression

514 between the control group and the Akt inhibitor treatment group. 
A a
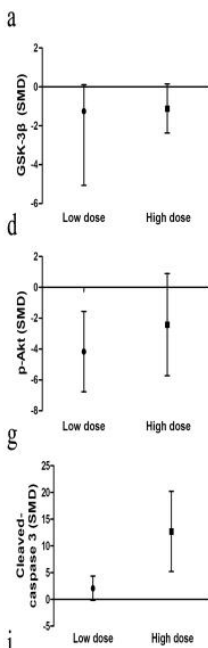

j

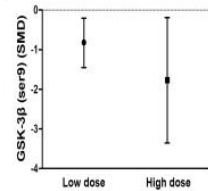

b
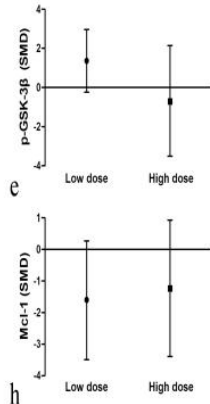

h Low dose High dose
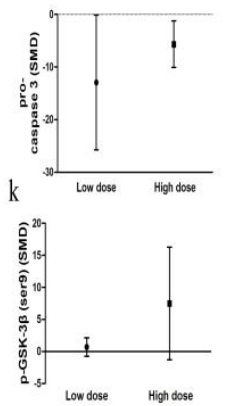

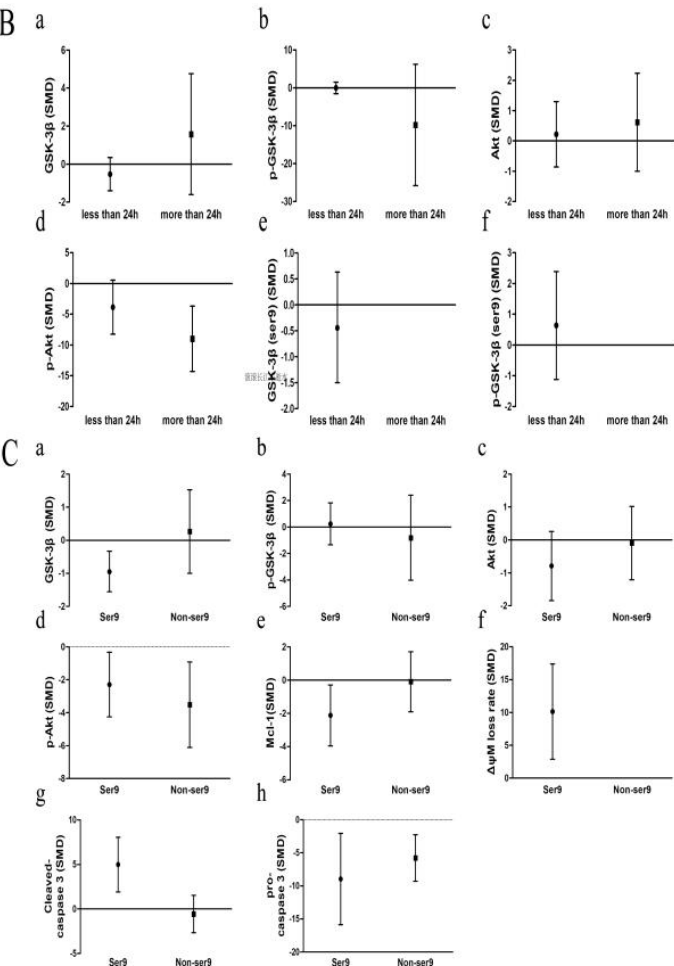

515 Figure 5. Subgroup analysis of arsenic exposure dose. SMD, standardized mean difference. GSK-3ß, Glycogen Synthase Kinase 3ß; Akt, protein kinase B; Mcl-1, myeloid cell leukemia-1; Bak, Bak BH3 peptide complex; $\Delta \psi \mathrm{M}$, mitochondrial membrane

517 potential; caspase-3, cysteinyl aspartate specific proteinase-3; Bax, Bcl-2-associated X protein; The two endpoints of the line

518 segment represent the upper and lower limits of the $95 \%$ CI, respectively, the midpoint of the line segment represents the

519 combined effect size (SMD). If the $95 \%$ CI contains 0 , it means that the combined effect size is not statistically significant. (A) sites exposed to arsenic. 

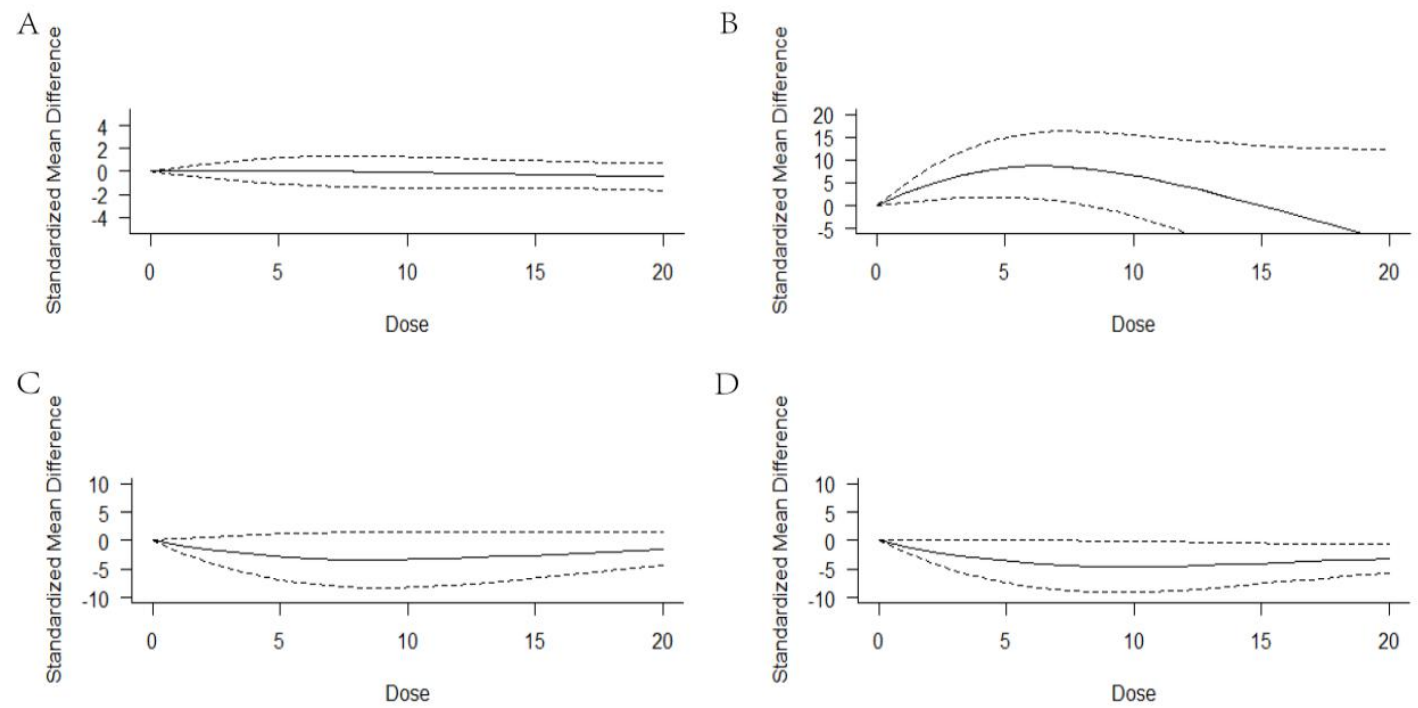

D

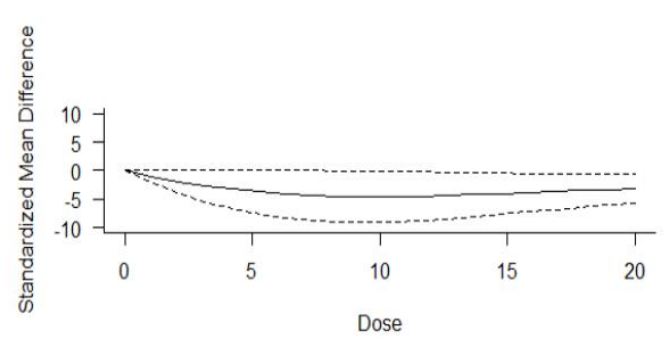

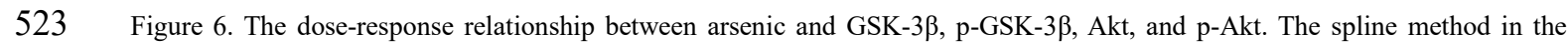

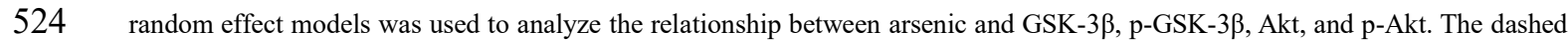
line represents $95 \% \mathrm{CI}$ of the spline model, and the solid line represents the standardized mean difference. (A) The dose-effect

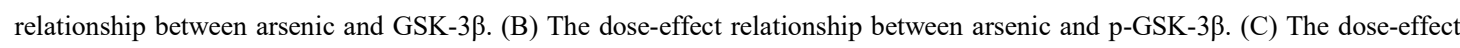
relationship between arsenic and Akt. (D) The dose-effect relationship between arsenic and p-Akt. 
A

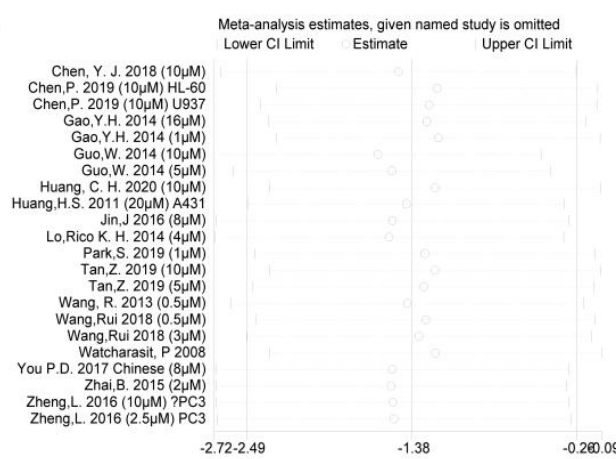

B



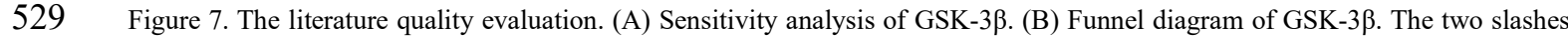
are the $95 \%$ confidence interval of the funnel chart, and the blue dashed line represents the standard mean deviation of the overall estimate after merging. SMD, standardized mean difference; SE, standard deviation. 







\section{Figures}

265 articles obtained by database serarch $(n=246)$ :Pubmed $(n=23)$,

Web of science ( $n=28)$, Embase $(n=32)$, Cochrane Library

$(n=0), C N K I(n=3)$, Wan Fang $(n=156)$, Viper $(n=4)$, SinMed $(n=19)$

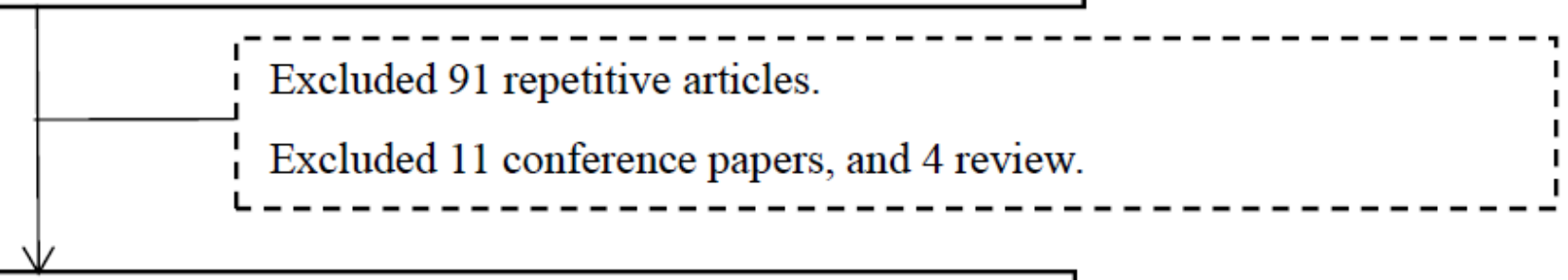

Read the titles and abstracts for preliminary screening $(\mathrm{n}=158)$



Figure 1

The flow chart for determining the final literature included in the meta-analysis. 



D



Figure 2

The effect of arsenic on apoptosis-related proteins. SMD, standardized mean difference; PARP, poly ADPribose polymerase; caspase-3, cysteinyl aspartate specific proteinase-3; caspase -9 , cysteinyl aspartate specific proteinase-9; Bcl-2, B-cell lymphoma 2 ;Bax, Bcl-2-associated X protein. Mcl-1, myeloid cell leukemia-1; Bak, Bak BH3 peptide complex; $\Delta \psi \mathrm{M}$, mitochondrial membrane potential; Cyt c, cytochrome c; cyto, cytoplasmic; mito, Mitochondrial; (A) Risk of bias graph. This study included 19 articles with a lowrisk rate of more than 75 percent. (B) The effect of arsenic on apoptosis-related proteins. (C) Bak, Mcl-1 and P-Mcl-1 expression in arsenic- exposed group and control group. (D) In the arsenic-exposed group and control group, the expression of the $\Delta \psi \mathrm{M}$ loss rate, cytochrome $\mathrm{C}$ and mitochondrial cytochrome $\mathrm{C}$. 

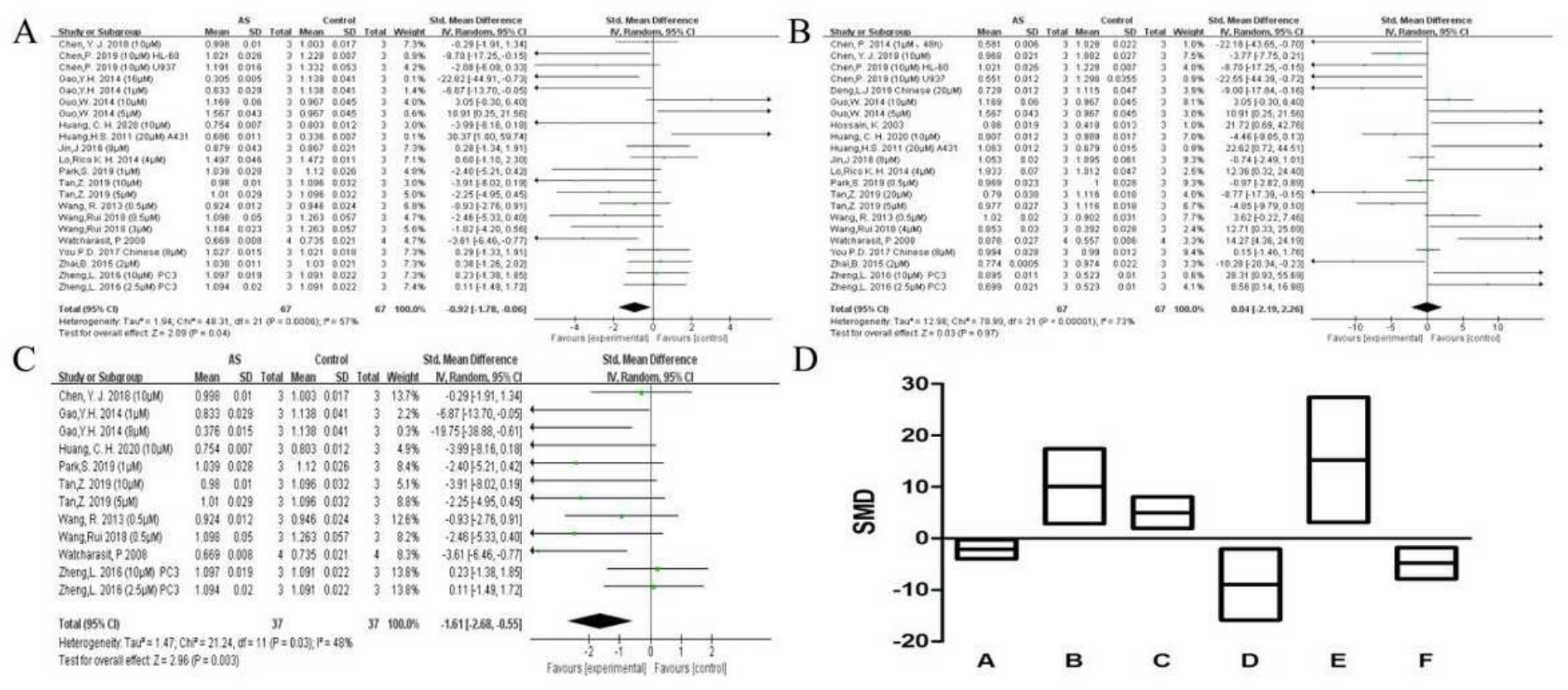

Figure 3

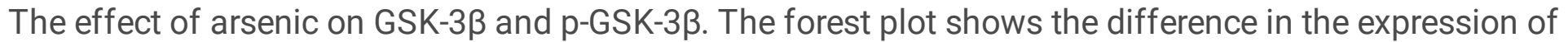
GSK-3 $\beta$ and $p-G S K-3 \beta$ between the control group and the arsenic-exposed group. SMD, standardized

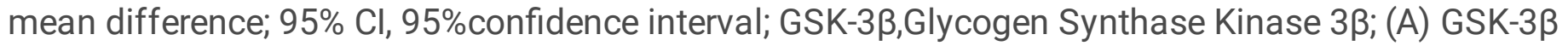
expression between the control group and the arsenic-exposed group. (B) The expression of p-GSK-3 $\beta$ between the control group and the arsenic-exposed group. (C) The effect of arsenic on GSK-3 $\beta$ (Ser9). (D) The effect of arsenic on GSK-3 $\beta($ Ser9) downstream apoptotic factors; A, Mcl-1; B, $\Delta \psi M$ loss rate; $C$, cleaved -caspase3; D, pro-caspase -3; E, cleaved-caspase-9; F, pro-caspase-9. 


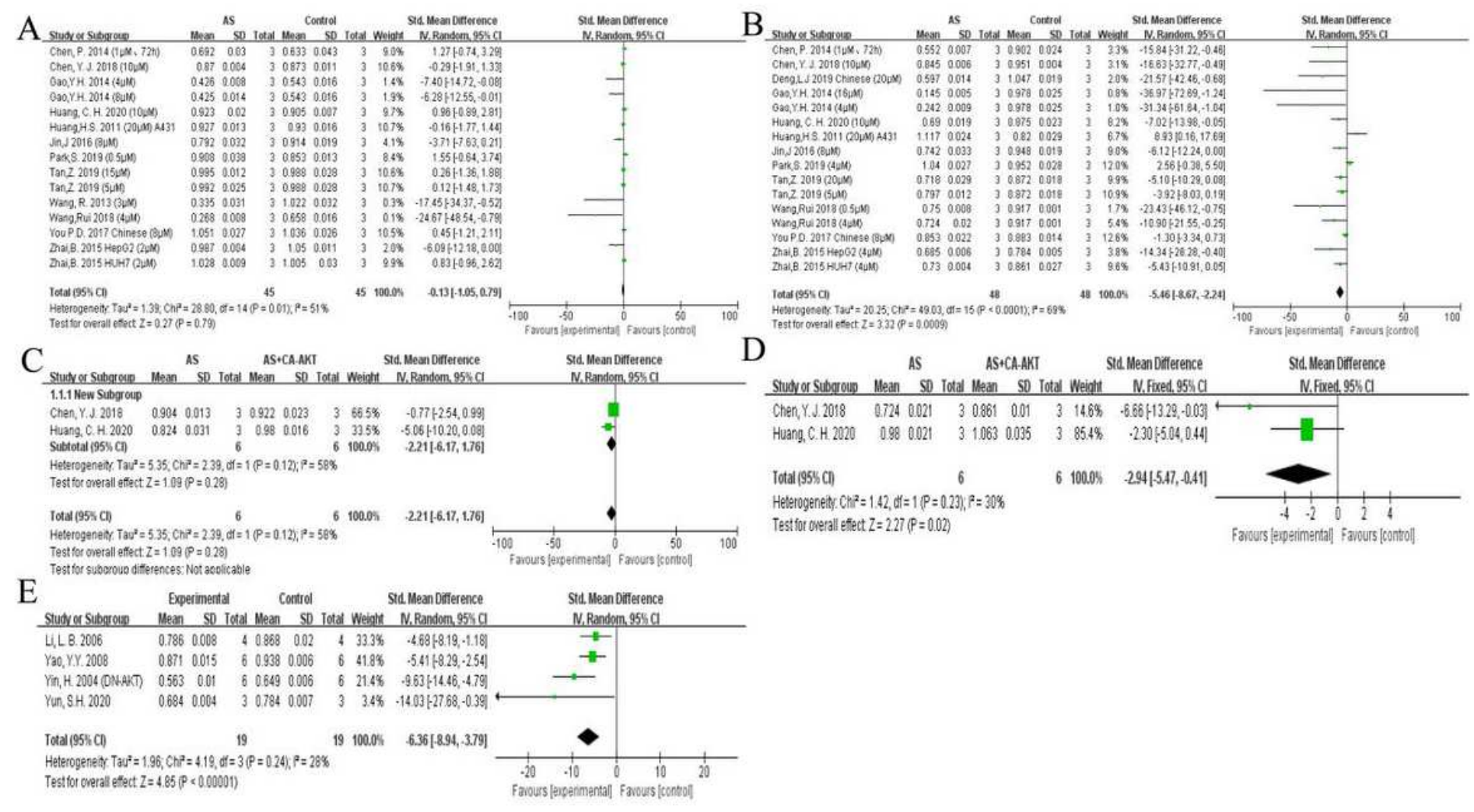

\section{Figure 4}

The effect of arsenic on Akt and p-Akt. The forest plot shows the difference between Akt and p-Akt expression between the control group and the arsenic-exposed group. SMD, standardized mean difference; $95 \% \mathrm{Cl}, 95 \%$ confidence interval; Akt, protein kinase B; (A) the expression of Akt between the control group and the arsenic-exposed group. (B) the expression of P-Akt between the control group and the arsenic-exposed group. (C) GSK-3 $\beta$ expression between the arsenic-exposed group and the combined treatment group with arsenic and Akt agonist. (D) The expression of p-GSK-3 $\beta$ between the arsenicexposed group and the combined treatment group with arsenic and Akt agonist. (E) The forest plot shows the difference in GSK-3ß expression between the control group and the Akt inhibitor treatment group. 
A a



d

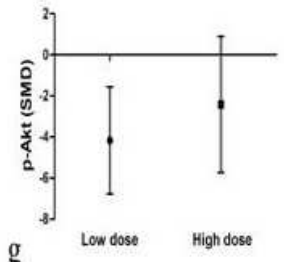

g


b
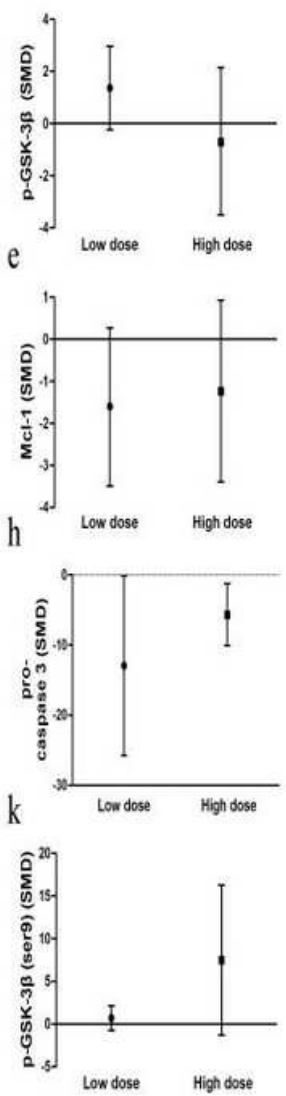

B a
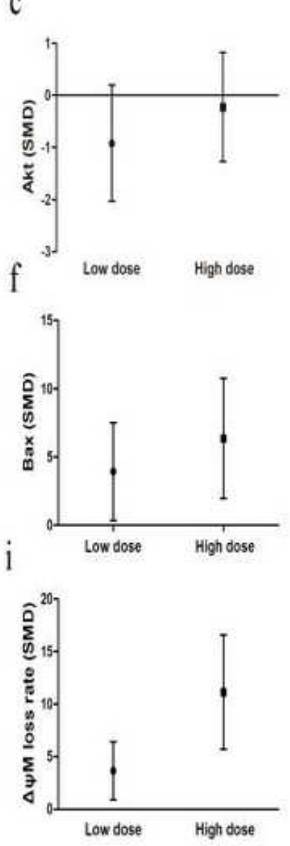
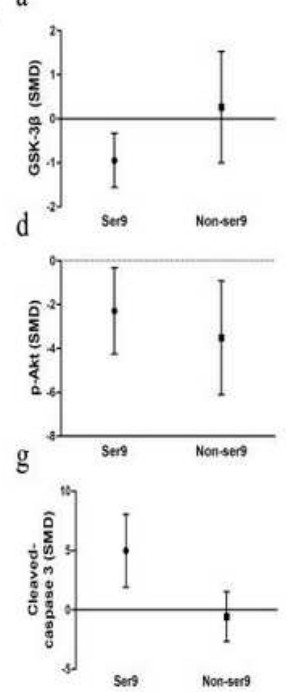

b


b
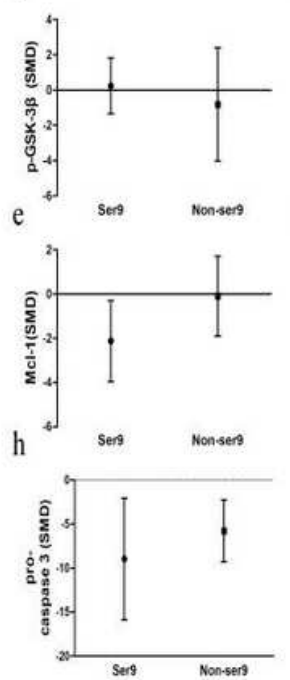

C
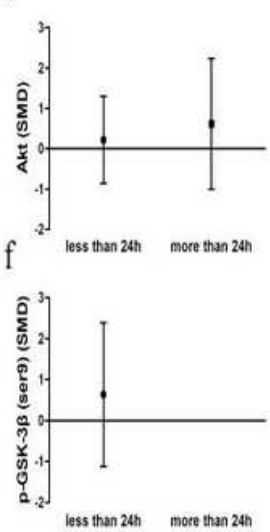

。


\section{Figure 5}

Subgroup analysis of arsenic exposure dose. SMD, standardized mean difference. GSK-3ß, Glycogen Synthase Kinase 3ß; Akt, protein kinase B; Mcl-1, myeloid cell leukemia-1; Bak, Bak BH3 peptide complex; $\triangle \psi \mathrm{M}$, mitochondrial membrane potential; caspase-3, cysteinyl aspartate specific proteinase-3; Bax, Bcl-2associated $X$ protein; The two endpoints of the line segment represent the upper and lower limits of the $95 \% \mathrm{Cl}$, respectively, the midpoint of the line segment represents the combined effect size (SMD). If the $95 \% \mathrm{Cl}$ contains 0 , it means that the combined effect size is not statistically significant. (A) Subgroup analysis of arsenic exposure dose. (B) Subgroup analysis of arsenic exposure time. (C) Subgroup analysis of GSK-3 $\beta$ sites exposed to arsenic. 


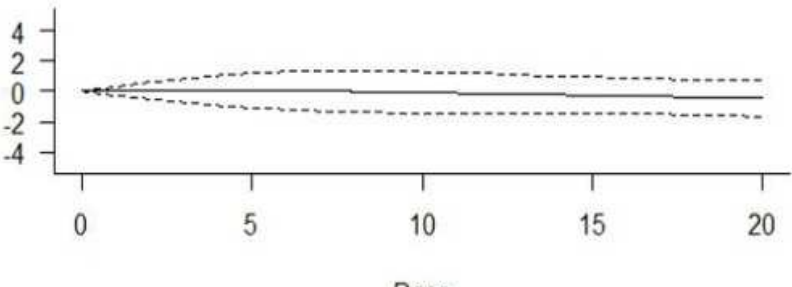

B

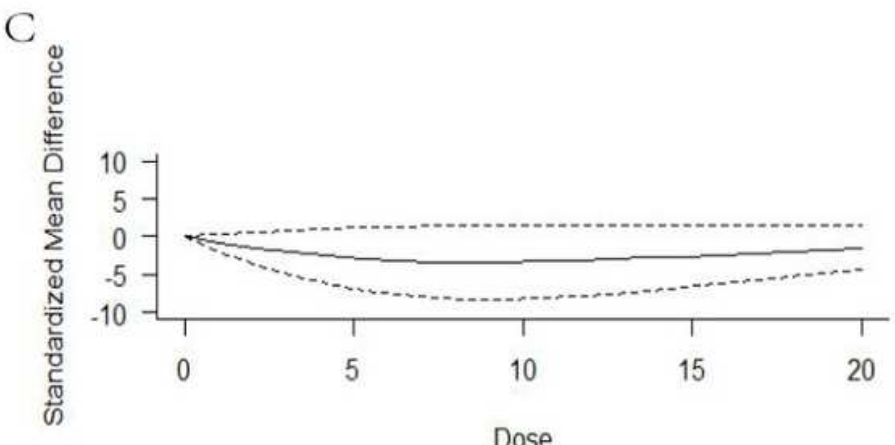

D

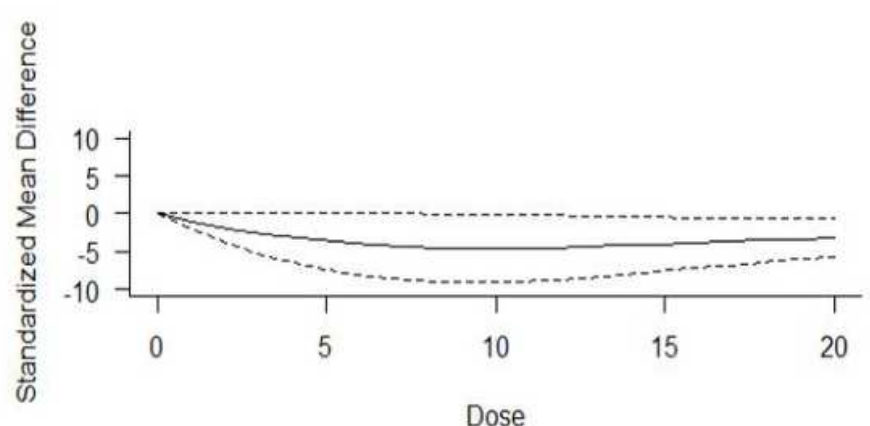

Figure 6

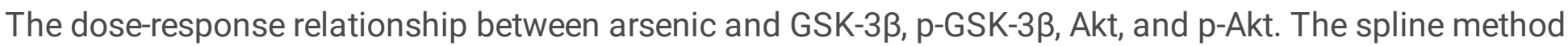

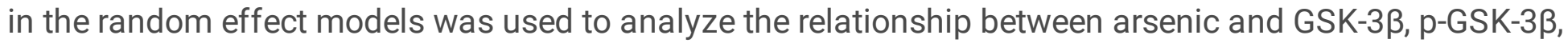
Akt, and p-Akt. The dashed line represents $95 \% \mathrm{Cl}$ of the spline model, and the solid line represents the standardized mean difference. (A) The dose-effect relationship between arsenic and GSK-3 $\beta$. (B) The dose-effect relationship between arsenic and p-GSK-3 $\beta$. (C) The dose-effect relationship between arsenic and Akt. (D) The dose-effect relationship between arsenic and p-Akt.

A

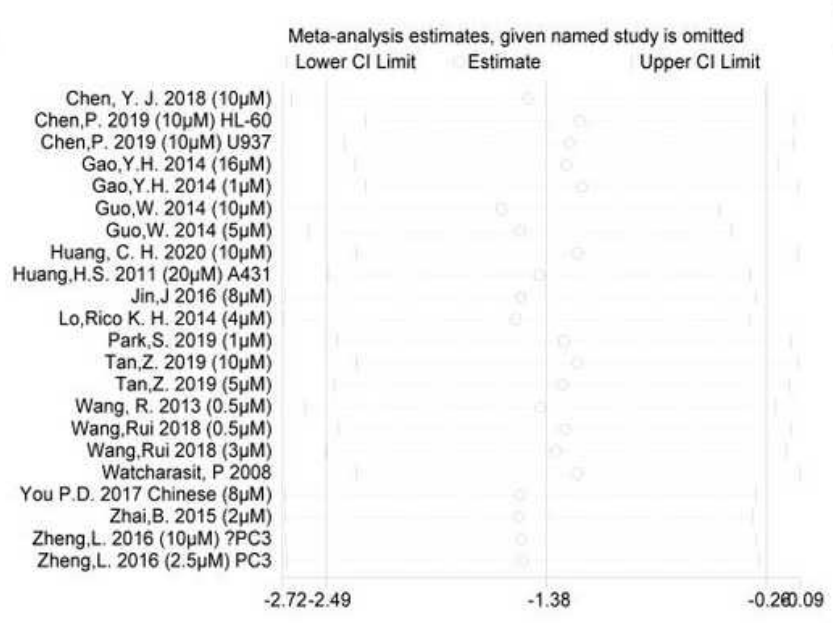

B

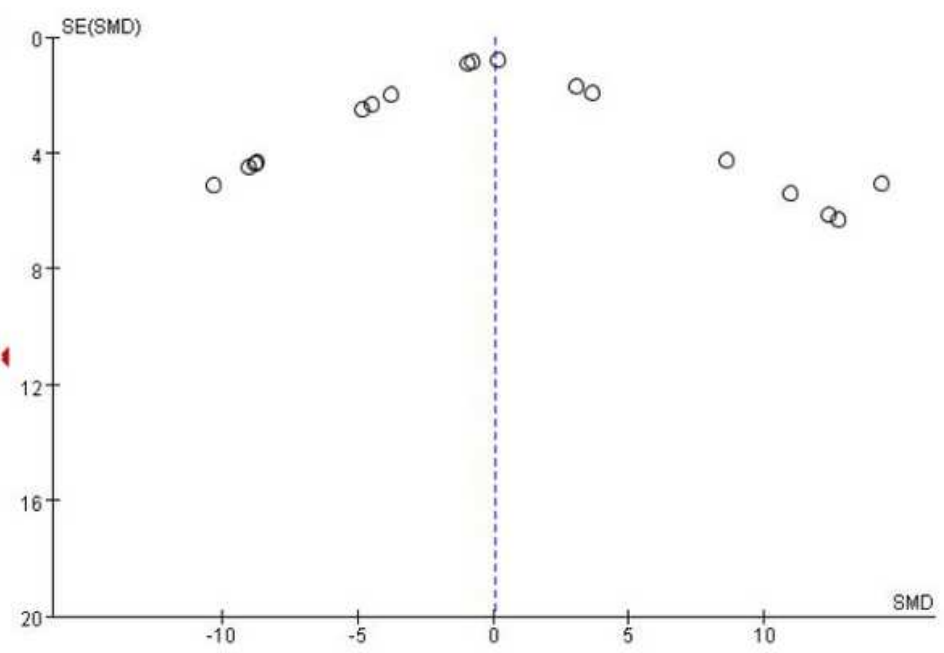

\section{Figure 7}




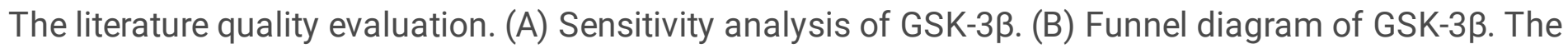
two slashes are the $95 \%$ confidence interval of the funnel chart, and the blue dashed line represents the standard mean deviation of the overall estimate after merging. SMD, standardized mean difference; SE, standard deviation.

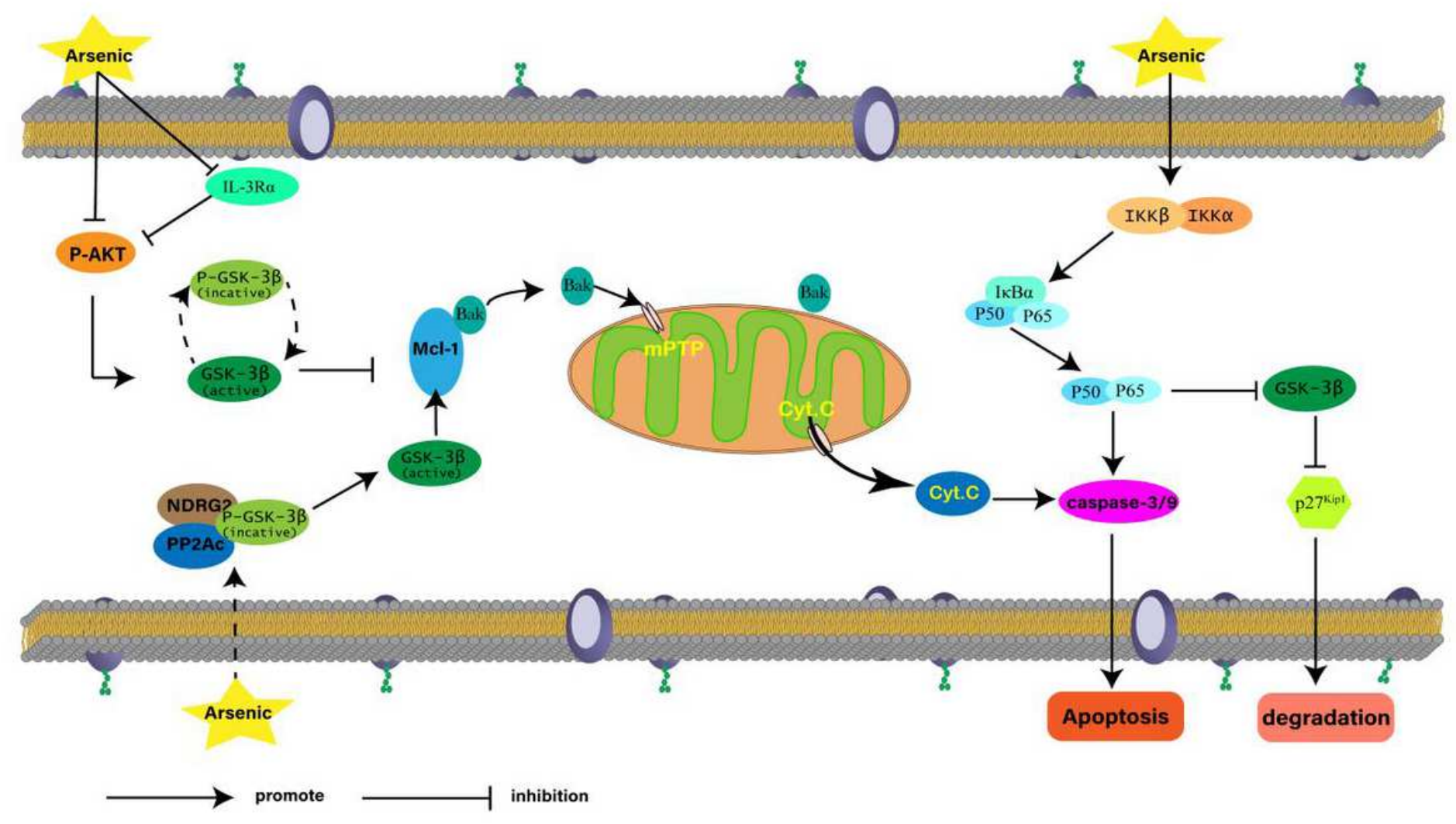

\section{Figure 8}

Mechanism diagram of GSK-3 $\beta$ inducing apoptosis of malignant tumor cells through arsenic.

\section{Supplementary Files}

This is a list of supplementary files associated with this preprint. Click to download.

- Data.xlsx 